\title{
Comparison of Magnesium Sulfate and Nifedipine in Prevention of Preterm Labor
}

\author{
Nahid Shahbazian ${ }^{1}$, Najmieh Saadati ${ }^{1} \&$ Mina Mahdavi ${ }^{1}$ \\ ${ }^{1}$ Department of Obstetrics and Gynecology, Ahvaz Jundishapur University of Medical Sciences, Ahvaz, Iran \\ Correspondence: Mina Mahdavi, Department of Obstetrics and Gynecology, Ahvaz Jundishapur University of \\ Medical Sciences, Ahvaz, Iran. E-mail: mina.m349@yahoo.com
}

Received: November 9, 2019

Accepted: January 5, 2020

Online Published: March 30, 2020

doi:10.5539/jmbr.v10n1p12

URL: https://doi.org/10.5539/jmbr.v10n1p12

\begin{abstract}
Introduction: Fetal and neonatal complications are more common in premature than full term pregnancy. Treatment of preterm labor and postpone delivery increases neonatal survival and better quality of life and reduces health care costs for premature infants. This study aimed to compare the effects of Nifedipine and Magnesium sulfate in arresting preterm labor and to adverse the effects of these drugs.

Materials and Methods: This randomized and clinical trial study was performed on 100 pregnant women who were hospitalized for preterm labor pain. The participants were pregnant women with the gestational age of 28 to 34 weeks and with a single pregnancy and symptoms of preterm were studied. They were randomly divided into two equal groups. After not suppressing the pain by fluid therapy, in the first group Magnesium sulfate infused injection $(\mathrm{N}=50)$ was performed, while in the second group, oral Nifedipine were given. The research uses SPSS software (version 20) statistical software issue 20 to analyze the result of tests with descriptive statistical methods including independent $\mathrm{T}$ test and chi square test.

Results: Mean maternal age, gestational age, parity converted Magnesium sulfate and Nifedipine group had no significant difference in statistical analysis. Delivery was delayed more than 48 hours in $48 \%$ (24 person) of cases in the Magnesium sulfate group and in $72 \%$ (36 person) in Nifedipine group ( $\mathrm{p}=0.03$ ). A statistically significant difference in response to treatment was more in group of Nifedipine.

Conclusion: The results showed that Nifedipine is more effective than Magnesium sulfate in postponing delivery (more than 48 hours), producing minimal side effect, having adequate price and applying an easy use method. Therefore, Nifedipine, as a tocolytic, can be a good substitute for Magnesium sulfate in preterm labor treatment.
\end{abstract}

Keywords: Preterm Delivery, Nifedipine, Magnesium Sulfate

\section{Introduction}

Giving birth is one of the most amazing physiologic events in human life and it can be safe and pleasant in many circumstances, but in some situations it might end with known difficulties and complications for mother and her fetus. Pregnancy may be influenced by many factors (Valadbeigi et al., 2017). Preterm labor is one of these complications. (Saadati, Moramezi, Cheraghi, \& Sokhray, 2014) The care and treatment of birth complications of a premature baby costs a great deal annually and sometimes mental and psychological strokes can cause irreparable stress for families. In fact, the birth of a healthy and uncomplicated newborn is the primary goal of pregnancy. (Cunningham, Leveno, Bloom, Hauth, Gilstrap III, \& Wenstrom, 2005)

Due to the importance of the subject and the increasing prevalence of preterm delivery in recent years, many efforts and studies have been done to identify, prevent and treatment of preterm labor. Nevertheless, no progress in reducing the prevalence of preterm delivery has been achieved in developed countries over the past two decades and the successes have only been limited to the field of treatment. (Petraglia, Strauss, Gabbe, \& Wiess, 2007) Pyelonephritis, a history of abdominal and pelvic surgery, diabetes, urinary tract and genital tract infections are all contributing to the increased risk of preterm labor. (Chehre, Karaallahi, Eivazi, Borji, \& Safar, 2018)

All pregnant women are taught about the symptoms of premature labor by the antenatal care practice. Should uterine contractions occur, they are to be self-monitored, and if regular painful contractions are detected the women have to go to the hospital for examination. (Songthamwat, Nan, \& Songthamwat, 2018) 
Preterm delivery cannot be stopped, but can be postponed for a few days. With this delay, it can have a profound impact on the outcome of preterm labor, including mortality and morbidity of premature infant (in terms of Physically, mentally, and evolutionarily, the economic burden and complications that sometimes persist throughout life) (Saadati, Moramezi, Cheraghi, \& Sokhray, 2014; Moore, 2003)

Uterine contractions are produced by the effects of prostaglandins. Prostaglandins are a group of paracrine hormones so they act where they produce. Prostaglandin producing by the decidua and fetal membranes might be one of the essential events of parturition that is followed by initiation of the uterine contraction. It seems likely that prevention of producing prostaglandins or suppression of their effects can stop preterm uterine contraction. (Saadati, Moramezi, Cheraghi, \& Sokhray, 2014)

Conventional treatment options for postponing preterm labor include bed rest, fluid therapy and sedation, and tocolytic agents, that each of these has its advantages and disadvantages. However, no convincing evidence has been provided as to the effectiveness of bed rest and hydration. (Saadati, Moramezi, Cheraghi, \& Sokhray, 2014; Scott, Gibbs, Karlan, \& Haney, 2003)

Several tocolytic agents are used for uterine contractions. Therefore, prior counseling, training and screening before and during pregnancy can help identify these factors that affect preterm labor. In preterm labor with cervical dilatation, the efficacy of tocolytics was proven for prolonging pregnancy. (Songthamwat, Nan, \& Songthamwat, 2018) The tocolytic that is most commonly used in our country is Magnesium sulfate. Magnesium works by competing with calcium or by reducing calcium entry into the cell through cell membranes during depolarization. According to recent studies, since this drug has been known to cause maternal complications (such as nausea and vomiting, lethargy, dyspnea, headache, hypotension, and dizziness (Kim et al., 2018)) and fetal complications (as respiratory depression, hypotonia, and hyporeflexia (W. H. Kim, Y. H. Kim, An, Moon, Noh, \& J. W. Kim, 2018)), and contradictory reports on its efficacy and cost, in most prestigious research centers around the world has been deleted from preterm labor treatment. In fact, Magnesiom sulfate has been replaced by some drug like a calcium channel blocker group called Nifedipine with better efficacy, faster rate of action, less side effects and less costs. (Taherian \& Dehdar, 2007)

Nifedipine inhibits myometrial contraction by blocking calcium entry into smooth muscle cells and by blocking voltage-dependent calcium channels. Many studies have now suggested that tocolytics is the preferred treatment for preterm labor. (Cunningham, Leveno, Bloom, Hauth, Gilstrap III, \& Wenstrom, 2005)

However the use of Nifedipine is associated with some side effects such as a headache, dizziness, flushing, and peripheral edema, and is contraindicated in women with hypotension, congestive heart failure, and aortic stenosis. (Haghighi, Rashidi, Najmi, Homam, Hashemi, Mobasseri, \& Moradi, 2017)

In general, medicine prescribed for pregnant mother has a therapeutic effect (Afiqah Amani et al., 2017). Clinicians are often faced with the problem of managing an established preterm labor with a variety of drugs which may have a lack of uterospecificity, low efficiency or potentially severe side effects for the mother or the unborn baby. (Moramezi, Barati, Saadati, Masihi, \& Hemadi, 2011)

Therefore, in this study, by considering the potential of delaying preterm labor and its effects, comparison was made between Magnesium sulfate and Nifedipine.

In case of achieving similar results to those reported in recent reports, based on better efficacy and fewer side effects of Nifedipine, It can be a suitable replacement for Magnesium sulfate in the treatment of preterm labor.

\section{Method}

This study is a phase 2 randomized clinical trial on 100 pregnant women with gestational age of 28 to 34 weeks who have been admitted to Imam Khomeini Hospital in Ahwaz since 2017 years with the diagnosis of preterm labor. It has been done after obtaining consent and in accordance with the inclusion criteria (At least 3 contractions lasting 30 seconds for 20 minutes with increased dilatation and cervical effacement) and exclusion criteria (All those who continuation of pregnancy to have contraindications or have problems with the administration of Nifedipine or Magnesium sulfate).

In this study, vital signs are checked first for all patients, 500cc Ringer is then administered with a rapid infusion and Then, if the uterine contractions continue, The patient was randomly assigned to either group A or Nifedipine $(\mathrm{n}=50)$ or group B or Magnesium sulfate $(\mathrm{n}=50)$. Then Nifedipine is administered with an initial dose of $20 \mathrm{mg}$ orally and then every 6 hours for 24 hours and Magnesium sulfate is administered intravenously at $4 \mathrm{mg}$ and then $2 \mathrm{~g} / \mathrm{h}$ for 24 hours.

In this study, for blinding, the Nifedipine group received ringer serum in addition to the oral drug and 
Magnesium sulfate recipient group receive oral placebo in addition to injectable drug. As such, the patient, physician, and treatment staff of the pationts under study have no knowledge of how individuals are placed in groups.

Thereafter, a check is made between initiation of treatment to relieve pain or the occurrence of preterm labor. During the study, vital signs, vaginal bleeding, rupture of fetal membrane, heart rate, uterine contractions and maternal blood pressure are monitored.

Midwifery information about the pregnant woman and her examinations and the type of prescription medication, as well as side effects and cases of treatment failure and interval between initiation of treatment and improvement of pain or stillbirth will be recorded in the questionnaire. In the cases in which the induction of labor due to fetal distress or other causes have occurred, the information is excluded.

Variables such as maternal age, gestational age, number of deliveries, history of preterm labor, rate of cervical dilatation and effacement, severity of uterine contractions, duration between onset of preterm labor until initiation of treatment, and duration between initiation of treatment to improvement of pain or delivery measured and examined.

To describe the data, the mean and standard deviation of the quantitative variables and the frequency and percentage of the qualitative variables are used.

For data analysis, t-test (Mann-Whitney if necessary), chi-square test and if necessary, logistic regression and survival analysis method were used.

All analyzes were performed using SPSS software version 20 and $\mathrm{P}<0.05$ was considered statistically significant.

\section{Results}

Based on the results of 100 pregnant women with gestational age of 28-34 weeks who were randomly divided into Nifedipine and Magnesium sulfate groups, there was no statistically significant difference in maternal age, gestational age, number of previous deliveries, dilatation and cervical effacement at the start of treatment and number of uterine contractions. (Table 1).

Table 1. Comparison of clinical and demographic characteristics of Nifidipine group and Magnesium sulfate group

\begin{tabular}{llll}
\hline Variables & $\begin{array}{l}\text { Nifedipine group } \\
\text { Mean+/- SD }\end{array}$ & $\begin{array}{l}\text { Magnesium sulfate group } \\
\text { Mean+/- SD }\end{array}$ & P value \\
\hline Maternal age (year) & $24.4+/-5 / 13$ & 0.88 & $23.8+/-5.43$ \\
Gestational age( week) & $31.6+/-1.8$ & 0.14 & $30.6+/-2.7$ \\
Number of previous deliveries & $1.5+/-0.97$ & 0.10 & $1.8+/-1.2$ \\
Cervical dilatation( Cm) & $1.5+/-0.5$ & 0.14 & $1.6+/-0.49$ \\
Cervical effacement( $\%)$ & $35.5+/-10.01$ & 0.96 & $38+/-9.47$ \\
Number of uterine contractions & $4.91+/-0.66$ & 0.51 & $5.2+/-0.45$ \\
\hline
\end{tabular}

The duration mean (+/- SD) duration between the onset of preterm labor and until treatment begins, was 35.42 $+/-32.52$ hours in women receiving Nifedipine and 34.48+/- 34.46 in women receiving Magnesium sulfate, that means the difference in time distribution between the two groups was not statistically significant. The duration mean (+/- standard deviation) between the start of treatment and the recovery of preterm labor was $14.32+/-$ 15.39 hours in the Nifedipine group and $15.86+/-14.72$ hours in the Magnesium sulfate group. Statistical analysis showed that there was a significant difference between the two groups $(p=0.01)$. However, there was no statistically significant difference between the two groups in the duration between treatment initiation and preterm delivery. $(\mathrm{p}=0.473)$ (Table 2$)$

Table 2. Frequency distribution of treatment response in the Nifedipine and Magnesium sulfate groups

\begin{tabular}{llll}
\hline Variables & Nifedipine group & Magnesium sulfate group & P value \\
\hline Duration between the onset of preterm labor and until treatment begins(h) & $35.42+/-32.52$ & $34.48+/-34.46$ & 0.668 \\
Time between the start of treatment and the recovery of preterm labor(h) & $14.32+/-15.39$ & $15.86+/-14.72$ & 0.01 \\
Time between treatment initiation and preterm delivery(h) & $16.7+/-13.97$ & $16.3+/-14.63$ & 0.473 \\
\hline
\end{tabular}


In 36 pationts (72\%) of Nifedipine group and 24 pationts (48\%) of Magnesium sulfate group, delivery was delayed more than 48 hours, which was statistically significant $(p=0.03)$ and Also in delayed delivery for less than 48 hours, there was 14 cases (28\%) in the Nifedipine group and 26 cases $(52 \%)$ in the Magnesium sulfate group $(\mathrm{p}=0.04)($ Table 3$)$.

Table 3. Frequency distribution of treatment response in the Nifedipine and Magnesium sulfate groups

\begin{tabular}{llll}
\hline \multirow{2}{*}{ group } & delayed delivery for less than 48 hours & delayed delivery for less than 48 hours & $\begin{array}{l}\text { Total } \\
\text { person }(\%)\end{array}$ \\
\hline Magnesium sulfate & $\mathbf{2 6}(\mathbf{5 2} \%)$ & $\mathbf{2 4}(\mathbf{4 8 \%})$ & $\mathbf{5 0}(\mathbf{1 0 0 \% )})$ \\
Nifedipine & $\mathbf{1 4}(\mathbf{2 8 \%})$ & $\mathbf{3 6}(\mathbf{7 2 \%})$ & $\mathbf{5 0}(\mathbf{1 0 0 \% )})$ \\
P value & $\mathbf{0 . 0 4}$ & $\mathbf{0 . 0 3}$ & - \\
\hline
\end{tabular}

Chi-square test showed a statistically significant difference in complications in the two groups of Nifedipine and Magnesium sulfate. $(\mathrm{p}<0.00001)$ (Table 4)

Table 4. Comparison abundance of complications between patients in the two groups of Nifedipine and Magnesium sulfate

\begin{tabular}{lllllll}
\hline complications & \multicolumn{2}{c}{ have } & \multicolumn{2}{c}{ Have not } & \multicolumn{2}{c}{ Total } \\
abundance & number & $\%$ & number & $\%$ & number & $\%$ \\
\hline Nifedipine group & 12 & 24 & 38 & 76 & 50 & 50 \\
Magnesium sulfate group & 26 & 52 & 24 & 48 & 50 & 50 \\
Total & 38 & 38 & 62 & 62 & 100 & 100 \\
\hline
\end{tabular}

The most common complications in Magnesium sulfate-treated group were hot flashes (32\%) and headache (8\%) and in the Nifedipine-treated group hypotension (10\%) and dizziness $(8 \%)$. None of the two groups had a serious maternal complication leading to discontinuation of treatment. (Table 5)

Table 5. Frequency of complications according to Nifedipine and Magnesium sulfate treatment groups

\begin{tabular}{lllllll}
\hline group & \multicolumn{2}{c}{ Magnesium sulfate } & \multicolumn{2}{c}{ Nifedipine } & \multicolumn{2}{c}{ Total } \\
& number & $\%$ & number & $\%$ & number & $\%$ \\
\hline Headache & 4 & 8 & 1 & 2 & 5 & 5 \\
Dizziness & 3 & 6 & 4 & 8 & 7 & 7 \\
Hypotension & - & - & 5 & 10 & 5 & 5 \\
Tachycardia & - & - & 1 & 2 & 1 & 1 \\
Hot flashes & 16 & 32 & - & - & 16 & 16 \\
Nausea \& vomoting & 3 & 6 & - & - & 3 & 3 \\
Dyspnea & - & - & - & - & - & 1 \\
Palpitation & - & - & 1 & 2 & 1 & 3 \\
Total & 26 & 52 & 12 & 24 & 38 & 38 \\
\hline
\end{tabular}

\section{Discussion}

Prevention and treatment of preterm labor is essential to reduce undesirable neonatal complications and increase survival and quality of life. In fact, the ultimate goal of preterm birth management is not just to prolong pregnancy, but to improve neonatal outcomes and reduce morbidity and mortality.

For this reason, we should try to prevent preterm labor as much as possible by eliminating the underlying factor or suppressing uterine contractions. Therefore, the aim of this study was to compare the effect of Nifedipine and Magnesium sulfate in preventing preterm labor which findings showed that there was a statistically significant difference in response to treatment of the two groups, such as the Nifedipine group had a higher response to treatment.

None of the patients in the two groups had any complication leading to discontinuation of treatment. 
In a study in 2007 by Lille, the efficacy of the two drugs was similar in delaying delivery for 48 hours, and there were fewer maternal complications in the Nifedipine-receiving group (Lyell, Pullen, Campbell, Ching, Druzin, Chitkara, Burrs, Caughey, \& El-Sayad, 2007).

Dr. Faraji's study in 2013 in Iran, it was found that Nifedipine was more effective than Magnesium sulfate in delaying labor for more than 48 hours, which is consistent with the results of the current study. (Faraji, Asgharnia, Dalil Heyrati, \& Nemati, 2013)

Deirdre, in a study in 2007 at Stanford University, found that stopping contractions within Magnesium sulfate was better than Nifedipine during the first 48 hours $(87 \%$ compared to $72 \%$ at $p=0.01)$, but delayed labor and gestational age at delivery and neonatal major outcomes were similar in the two groups, the results of which are in contrast to our recent study, and Nifedipine was significantly associated with fewer maternal complications (Deirdre, Pullen, Campbell, Ching, Druzin, Chitkara, Burrs, Caughey, \& EL-Sayed, n. d.).

In a 1999 study by Dr. Haghighi at the University of Tehran, Nifedipine and Magnesium sulfate both had similar efficacy and side effects, but Nifedipine had a faster effect on stopping uterine contractions, which is similar to the results of our study (Haghighi, 1981).

In another study by Glock in 2002, aimed to compare the effects of Nifedipine and Magnesium sulfate in patients with preterm labor, oral Nifedipine was as effective as Magnesium sulfate in stopping preterm labor, which is similar to our study's result showing that Nifedipine had a faster effect on preventing preterm labor. (Glock \& Morales, 2009)

In a study in 2013 by Dr Nikbakht in Iran, 100 women with documented preterm labor were randomly assigned to receive Magnesium sulfate $(\mathrm{n}=50)$ and Nifedipine $(\mathrm{n}=50)$ as tocolytic therapy. Both drugs were equally effective in prevention of labor and delaying delivery more than 7 days, $56 \%$ vs. $64 \%$ in the Nifedipine and Magnesium sulfate groups, and the days gain in utero was no statistically different in two groups. $6 \%$ of Nifedipine group and $2 \%$ of Magnesium sulfate group required drug discontinuation due to severe symptoms. There were also no significant differences in maternal characteristics between two groups. The total success rate and side effects were similar in two groups. (Nikbakht, Moghadam, \& Ghane'ee, 2014)

In the present study, Nifedipine has many benefits including fewer side effects, better tolerance and acceptance by the patient, and oral administration of intravenous infusion.

Side effects of Nifedipine are also dose dependent and rarely lead to intolerance and discontinuation of the drug. The most common complication is hypotension less than $90.50 \mathrm{mmHg}$ reported in the mother and is seen approximately 20 minutes after the second oral dose and is usually transient and not clinically significant, such that with adequate fluid therapy, it is preventable. (Jeyabalan \& Caritis, 2002)

In the present study, there were maternal adverse events in 12 patients (24\%) of Nifedipine group and 26 patients (56\%) of Magnesium sulfate group, which were statistically significant.

\section{Conclusion}

According to the results, Nifedipine can be a good substitute for Magnesium sulfate in preterm labor due to its good efficacy and low side effects, low cost and easy use as a tocolytic.

\section{Acknowledgments}

Finally, we thank all the staff of Imam Khomeini Hospital in Ahvaz who assisted in this research and also the support of the Vice Chancellor for Research of Ahvaz Jundishapur University of Medical Sciences

\section{Conflict of interests}

The authors declare that there is no conflict of interests regarding the publication of this paper.

\section{References}

Chehre, R., Karaallahi, Z., Eivazi, A., Borji, M., \& Safar, A. (2018). Prevalence of recurrence of preterm labor and its related factors in Ilam city. IJOGI, 21(10), 20-29.

Cunningham, R. G., Leveno, K. J., Bloom, S. L., Hauth, J. C., Gilstrap III, L., \& Wenstrom, K. D. (2005). William's obstetrics (22nd ed., pp. 857-870). New York: McGraw-Hill.

Deirdre, J. L. D. J., Pullen, K., Campbell, L., Ching, S., Druzin, M. L., Chitkara, U., Burrs, D., Caughey, A. B., \& EL-Sayed. (n. d.). Magnesium Sulfate compared with Nifedipine for acute tocolysis of preterm labor: A randomized controlled Trial. American College of Obstet \& Gynecol, 110, 5. 
Faraji, R., Asgharnia, M., Dalil Heyrati, S. F., \& Nemati, F. (2013). Comparison of Magnesium sulfate and Nifedipine in prevention of preterm labor. Journal of Babol University of Medical Sciences, 15(4), 88-92.

Glock, J. L., \& Morales, W. J. (2009). Efficacy and safety of Nifedipine versus Magnesium sulfate in the management of preterm labor: A randomized study. American Journal of Obstetrics and Gynecology, 169(4), 960-4.

Valadbeigi, T., Ahmadi Gharaei, H., ARajabi, A., Tabatabaee, H. R., Etemad, K., Soltani, M., ArabAhmadi, A., Salehnasab, C., Almasi, Z., Yaghoobi, H., Zolfizadeh, F., Ghasemi, A., Enayatrad, M., Mahdavi, S., Hajipour, M. (2017). The relationship between physical violence during pregnancy and stillbirth and neonatal mortality. Journal of Advanced Pharmacy Education \& Research, 7 (4), 450-459.

Haghighi, L. (1981). Prevention of Preterm Delivery: Nifedipine or Magnesium Sulfate. Journal of Iran University of Medical Sciences, 6(3), 30-5.

Haghighi, L., Rashidi, M., Najmi, Z., Homam, H., Hashemi, N., Mobasseri, A., \& Moradi, Y. (2017). Comparison of intramuscular progesterone with oral Nifedipine for treating threatened preterm labor: A randomized controlled trial. Med J Islam Repub Iran, 31, 56.

Jeyabalan, A., \& Caritis, S. N. (2002). Pharmacologic inhibition of preterm labor. Clin Obstet Gynecol, 45(1), 99-113.

Kim, M. K., Lee, S. M., Oh, J. W., Kim, S. Y., Jeong, H. G., Kim, S. M., .., \& Park, J. S. (2018). Efficacy and side effect of Ritodrine and Magnesium sulfate in threatened preterm labor. Obstet Gynecol Sci., 61(1), 63-70.

Kim, W. H., Kim, Y. H., An, Y., Moon, J H., Noh, E. J., \& Kim, J. W. (2018). Total and ionized serum magnesium and calcium levels during Magnesium sulfate administration for preterm labor. Obstet Gynecol Sci., 61(1), 56-62.

Afiqah Amani Binti Zaaba, N., Roy, A., Lakshmi, T. (2017). Perception of women on the adverse effect of drugs on the fetus during pregnancy. Journal of Advanced Pharmacy Education \& Research, 7(2), 72-75.

Lyell, D. J., Pullen, K., Campbell, L., Ching, S., Druzin, M. L., Chitkara, U., Burrs, D., Caughey, A. B., \& El-Sayad, Y. Y. (2007). Magnesium sulfate compared with Nifedipin for acute tocolysis of preterm labor: A randomized controlled trial. Obstet Gynecol, 110(1), 61-7.

Moore, M. L. (2003). Preterm labor and birth: What have we learned in the past two decades? J Obstet Gynecol Neonatal Nurs, 32(5), 638-49.

Moramezi, F., Barati, M., Saadati, N., Masihi, S., \& Hemadi, M. (2011). A Comparative Study between the Efficacy of 17-alpha-Hydroxy Progesterone Caproate plus Salbutamol with Magnesium Sulfate in treatment of preterm labor. International Journal of Pharmacology, 7(1), 130-134.

Nikbakht, R., Moghadam, M. T., \& Ghane'ee, H. (2014). Nifedipine compared to Magnesium sulfate for treating preterm labor: A randomized clinical trial. Iran J Reprod Med., 12(2), 145-150.

Petraglia, F., Strauss, J. F., Gabbe, S. G., \& Wiess, G. (2007). Complicated pregnancy (4th ed., pp. 668-700). London: Informa Healthcare.

Saadati, N., Moramezi, F., Cheraghi, M., \& Sokhray, L. (2014). Using Celecoxib for the suppression of preterm labor instead of Magnesium sulfate. Hindawi Publishing Corporation Journal of Pregnancy.

Scott, J. R., Gibbs, R. S., Karlan, B. Y., \& Haney, A. F. (2003). Danforth's obstetrics \& gynecology (9th ed., pp. 173-183). Philadelphia: Lippicott Williams \& Wilkins.

Songthamwat, S., Nan, C. N., \& Songthamwat, M. (2018). Effectiveness of Nifedipine in threatened preterm labor: A randomized trial. Int $J$ Womens Health, 10, 317-323.

Taherian, A. A., \& Dehdar, P. (2007). Comparison of efficacy and safety of Nifedipine versus Magnesium sulfate in treatment of preterm labor. J Res Med Sci., 12(3), 136-41.

\section{Copyrights}

Copyright for this article is retained by the author(s), with first publication rights granted to the journal.

This is an open-access article distributed under the terms and conditions of the Creative Commons Attribution license (http://creativecommons.org/licenses/by/4.0/). 